Article

\title{
One-Step Preparation of a VHH-Based Immunoadsorbent for the Extracorporeal Removal of $\beta 2$-microglobulin
}

\author{
Lijun Zhang, Berlin Zang, Chundong Huang, Jun Ren and Lingyun Jia *
}

Liaoning Key Laboratory of Molecular Recognition and Imaging, School of Bioengineering, Dalian University of Technology, No.2 Linggong Road, Dalian, Liaoning 116023, China; zhanglijun1022@mail.dlut.edu.cn (L.Z.); dutberlin@mail.dlut.edu.cn (B.Z.); cd_huang_bio@mail.dlut.edu.cn (C.H.); renjun@dlut.edu.cn (J.R.)

* Correspondence: lyjia@dlut.edu.cn; Tel.: +86-411-84706125; Fax: +86-411-84706125

Academic Editor: José Manuel Herrero-Martínez

Received: 14 May 2019; Accepted: 3 June 2019; Published: 4 June 2019

\begin{abstract}
Dialysis-related amyloidosis (DRA), which has been widely recognized to be associated with the accumulation of $\beta 2$-microglobulin ( $\beta 2-\mathrm{m})$ in blood, is one of the most common complications in patients receiving long-term dialysis treatment. The most significant side-effect of existing hemodialysis sorbents for the removal of $\beta 2-\mathrm{m}$ from blood is the loss of vital proteins due to non-specific adsorptions. Although the traditional antibodies have the capability to specifically remove $\beta 2-\mathrm{m}$ from blood, high cost limits their applications in clinics. Single domain antibodies derived from the Camelidae species serve as a superior choice in the preparation of immunoadsorbents due to their small size, high stability, amenability, simplicity of expression in microbes, and high affinity to recognize and interact with $\beta 2-\mathrm{m}$. In this study, we modified the anti- $\beta 2-\mathrm{m}$ VHH by the formylglycine-generating enzyme (FGE), and then directly immobilized the aldehyde-modified VHH to the amino-activated beads. Notably, the fabrication is cost- and time-effective, since all the preparation steps were performed in the crude cell extract without rigorous purification. The accordingly prepared immunoadsorbent with VHHs as ligands exhibited the high capacity of $\beta 2-\mathrm{m}(0.75 \mathrm{mg} / \mathrm{mL})$. In conclusion, the VHH antibodies were successfully used as affinity ligands in the preparation of novel immunoadsorbents by the site-specific immobilization, and effectively adsorbed $\beta 2-\mathrm{m}$ from blood, therefore opening a new avenue for efficient hemodialysis.
\end{abstract}

Keywords: $\beta 2$-microglobulin; VHH; formylglycine-generating enzyme; hemodialysis

\section{Introduction}

The kidney plays a central role in the removal of metabolic wastes from our bloodstream by making urine. However, chronic kidney disease, which involves persistent kidney injury or glomerular filtration rate (GFR) lower than $60 \mathrm{~mL} / \mathrm{min}$ per $1.73 \mathrm{~m}^{2}$ for 90 days or longer, has been proven to be a primary fast-growing health problem around the world, contributing to the rising of kidney failure, cardiovascular disease (CVD), and premature death [1-3].

$\beta 2-$ Microglobulin $(\beta 2-\mathrm{m})$, a highly conserved globular protein $(11.8 \mathrm{kDa})$, is a major middle-molecular uremic toxin. $\beta 2-\mathrm{m}$ is a component of the major histocompatibility complex on almost all nucleated cell membranes, which can detach from the membrane and eventually be catabolized in renal tubules. However, the pathological concentration of $\beta 2-\mathrm{m}$ in hemodialysis patients might rise to a level that is 50 times higher than that under normal conditions [4]. Traditional hemodialysis devices fail to eliminate $\beta 2$-m from blood, and thus lead to the long-term accumulation of $\beta 2-\mathrm{m}$ in serum or systemic organs [5]. The resulting deposits have been identified as dialysis-related amyloidosis (DRA) [6]. Symptoms in patients with DRA [7,8] mainly consist of joint pain, carpal tunnel 
syndrome (CTS), destructive spondyloarthropathy (DSA), and cystic bone lesions with associated fractures, which tremendously reduce patients' activity of daily living (ADL) [9]. Therefore, it is of vital importance to reduce the serum $\beta 2$-m concentration to healthy levels clinically. The aggressive removal of $\beta 2-\mathrm{m}$ has been proven useful in the prevention and remission of DRA [10]. Although several hemodialysis devices mimic the functions of kidney by hemodialysis, hemodiafiltration, and peritoneal dialysis, most of these non-specific technologies are unable to reach clinical remission [11].

Developing a high-specific adsorbent for $\beta 2-\mathrm{m}$ remains a central issue according to clinical assessments of different patients [12,13]. The first listed $\beta 2$-m selective adsorbent, Lixelle ${ }^{\mathrm{TM}}$ (Kaneka Co., Ltd., Osaka, Japan) [14], was designed to adsorb $\beta 2-m$ through the combination of hydrophobic interaction and applicable pore size. With the hydrophobic hexadecyl groups immobilized on the cellulose beads, Lixelle adsorbed not only $\beta 2-\mathrm{m}$ but also insulin, lysozyme, and retinol-binding proteins [15]. An in vitro study showed that inflammatory cytokines, such as interleukins IL-6 and IL1- $\beta$, were also adsorbed to the column [16]. To acquire a high $\beta 2-\mathrm{m}$ binding specificity, antibodies serve as superior candidates for the innovative hemodialysis strategies. The monoclonal antibody and $s c F v$-based immunoadsorbents [17] were fabricated recently for the removal of $\beta 2-m$ without causing significant loss of valuable proteins conducive to patients [18]. By possessing both high affinity to $\beta 2-\mathrm{m}$ and fast-apparent rate of adsorption, which are essential in consideration of the limited treatment time, the antibody-based immunoadsorbents could efficiently reduce the concentration of $\beta 2-m$ to a healthy level in blood [18]. Notwithstanding, the low stability and the high cost of the synthetic affinity ligands limits the applications of monoclonal antibody or scFv-based immunoadsorbents. Therefore, the development of cost-efficient affinity ligands with high-selectivity is of urgent need.

The VHHs, also referred to as single-domain antibodies or nanobodies [19], possess a small size (about $15 \mathrm{kDa}, 1 / 10$ of human IgG) [20], leading to higher densities and available antigen-binding sites on the adsorbent compared to traditional antibodies. VHHs usually possess high stability, high affinity, and low immunogenicity [21]. Furthermore, the VHHs can be obtained from Escherichia coli or yeast with high yields, which would potentially facilitate the cost-effective large-scale production of VHHs. These advantages of $\mathrm{VHH}$ antibodies, combined with the explicit affinity to $\beta 2-\mathrm{m}$, encouraged the attempted fabrication of a novel VHH-based immunoadsorbent.

Here we present a facile one-step method for the preparation of a VHH-based immunoadsorbent using the formylglycine-generating enzyme to introduce a site-specific aldehyde group that facilitates the subsequent site-specific immobilization at the C-terminus of VHH. The novel adsorbent showed a high specificity to $\beta 2-\mathrm{m}$. Meanwhile, combinatorial approaches based on VHH antibodies open a new avenue to the rapid, feasible, and low-cost synthesis of new synthetic affinity ligands of precise utilization with scale-up potential in the novel immunoadsorbent preparation.

\section{Results and Discussion}

\subsection{Expression of Recombinant VHHs and FGE}

A previous study confirmed a low productivity when aldehyde-tagged protein A was co-expressed with FGE to achieve the conversion of cysteine to formylglycine in vivo [22]. In this work, aldehyde-tagged VHH and histidine-tagged FGE were expressed in E. coli shuffle T7 and E. coli BL21 (DE3) separately to improve the expression level of each protein. The yield of the VHH was about $400 \mathrm{mg}$ per liter of cell culture. The purity of soluble VHHs in the cell extract was largely improved to about $60 \%$ after the acid-assisted precipitation of endogenous proteins, which was relatively conducive to the subsequent catalysis process (Figure 1). 


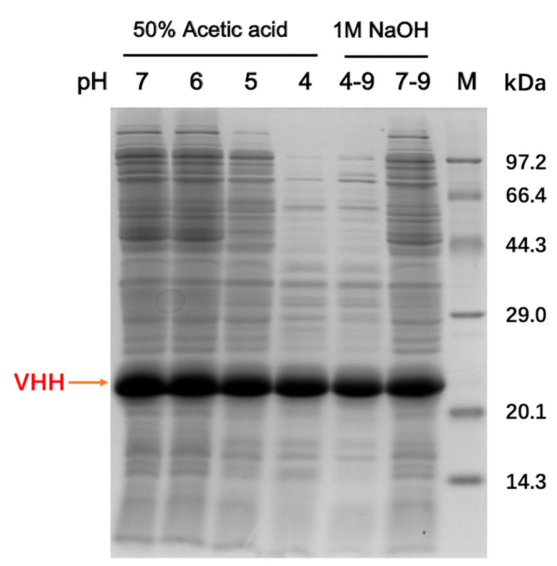

Figure 1. Acetic acid-assisted precipitation of host cell proteins. Lane M is the protein molecular weight marker; $50 \%$ acetic acid solution was added dropwise into the crude cell extract. The supernatant treated with different $\mathrm{pH}$ values were analyzed by SDS-polyacrylamide gel electrophoresis (SDS-PAGE) and gray scanning. After precipitation, the supernatant was readjusted to $\mathrm{pH} 9$ (Lanes 4-9). The lysate, which directly adjusted from $\mathrm{pH} 7$ to $\mathrm{pH}$ 9, was set as a control (Lanes 7-9).

FGE was expressed in E. coli BL21 (DE3) in soluble form, and the yield of FGE was about $300 \mathrm{mg}$ per liter of cell culture. Previous studies showed that $\mathrm{Cu}$ (II) played a crucial role in the catalytic activity of FGE [23-26], so $10 \mu \mathrm{M} \mathrm{CuSO}_{4}$ was added to the culture medium during the protein expression to improve the activity of FGE.

\subsection{Validation of the Site-Specific Aldehyde Modification}

A hydrazide-containing dye, Lucifer Yellow $\mathrm{CH}$ (LY-CH), was applied as a probe to validate the generation of the aldehyde group on the $\mathrm{VHH}$ fragment from the crude cell extract after catalysis, as hydrazide selectively reacts with aldehyde under acidic condition via hydrazone ligation. The labeled product was analyzed by SDS-PAGE, and the amount of aldehyde modified VHHs was calculated by gray scanning. As shown in Figure 2, VHH antibodies modified by FGE exhibited strong fluorescence under UV-light when labeled with LY-CH (Figure 2, Lanes 4-6). The yield of modified VHHs from the cell extract (61.4\%, Lane 4) was lower than that from the purified VHH/FGE mixture (90.4\%, Lane 5) under the same catalytic condition, possibly attributable to the disturbance of host cell proteins in cell extract, which hinder the interaction between FGE and the aldehyde tag on the VHH. An increase in the conversion efficiency was obtained by extending incubation time or increasing the dosage of FGE (Figure 3). Finally, the conditions were optimized to be: molar ratio of VHH and FGE of 10:1, concentration of DTT of $2 \mathrm{mM}$, catalytic temperature of $20^{\circ} \mathrm{C}$, incubation time of $12 \mathrm{~h}$, with catalytic efficiency of up to nearly $80 \%$, which are able to accomplish the subsequent coupling process. It was also demonstrated that the 6-mer amino acids sequence (LCTPSR) attached to the C-terminus of the anti- $\beta 2-m$ VHH was well recognized by FGE. Besides, there was no significant difference between the affinity constants of the modified and the unmodified VHH as measured by Biacore T200 (Figure 4), indicating that the aldehyde modification on VHHs did not harm the conformation or the activity of the protein of interest. 


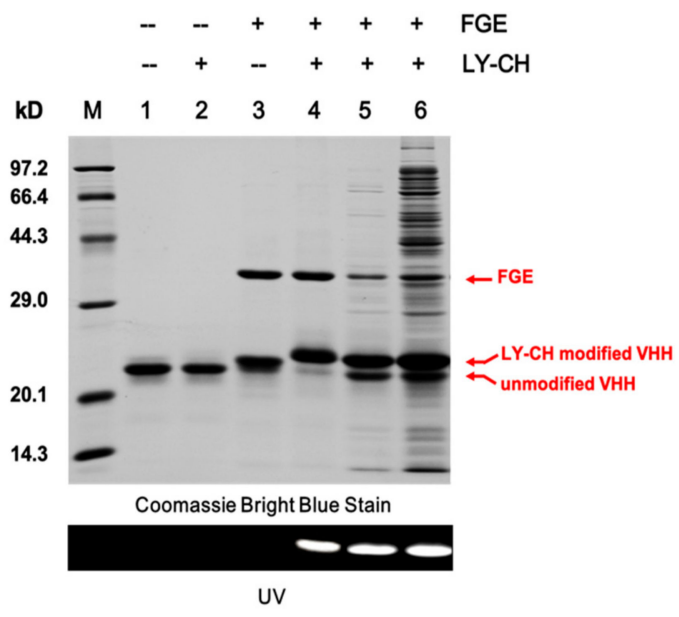

Figure 2. Validation of the site-specific modification of VHHs. SDS-PAGE analysis of Aldtag-VHH and the lucifer yellow $\mathrm{CH}(\mathrm{LY}-\mathrm{CH})$ labeled products. Lane M, molecular weight markers; lane 1, native Aldtag-VHH; lane 2, Aldtag-VHH incubated with LY-CH; lane 3, FGE modified Aldtag-VHH incubated without LY-CH; lane 4, FGE modified Aldtag-VHH incubated with LY-CH; lane 5, crude cell extract was pretreated with $50 \%$ acetic acid to $\mathrm{pH} 4$ with adjustment to $\mathrm{pH} 9$ with $1 \mathrm{M} \mathrm{NaOH}$; lane 6 , crude cell extract pretreated with $1 \mathrm{M} \mathrm{NaOH}$ (adjusted directly to $\mathrm{pH}$ 9).

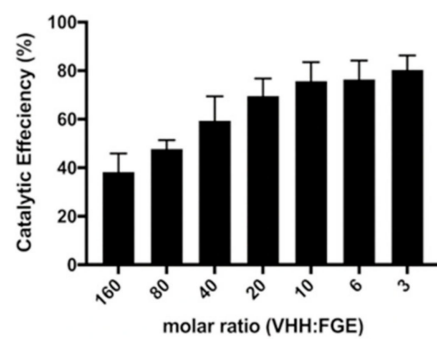

A

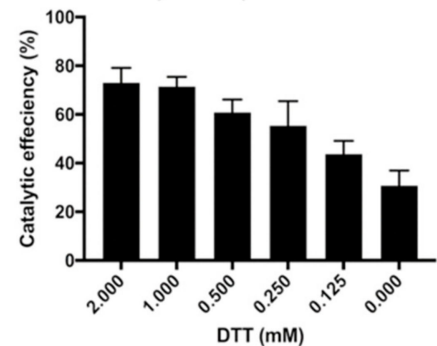

C

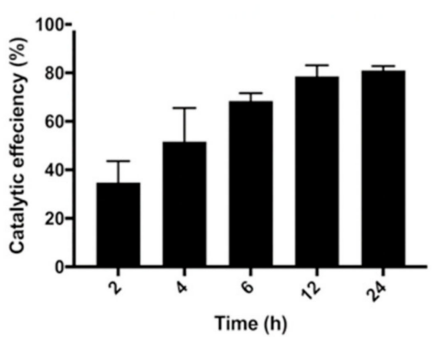

B

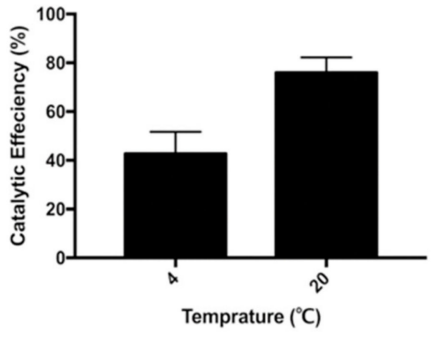

D

Figure 3. Optimization of FGE-catalytic conditions of VHH catalysis in the crude cell extract. Four factors were investigated, including (A) the molar ratio of VHH and FGE, (B) incubation time, (C) the concentration of DTT added to the catalytic buffer, and (D) the catalytic temperature. The products of VHH incubated with FGE under different conditions were analyzed by SDS-PAGE, and the catalytic efficiency was calculated using the software of ImageJ. Data are presented as means \pm SDs, $n=3$. Error bars are within symbol size if not visible. 


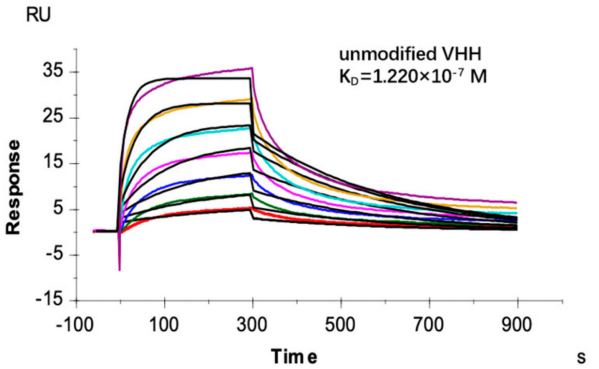

A

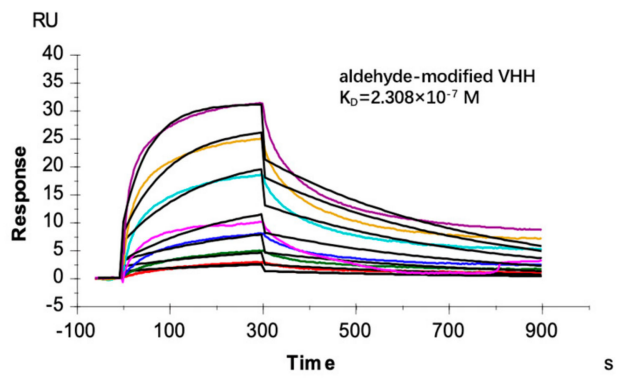

B

Figure 4. Affinities of the unmodified (A) and modified VHHs (B) binding $\beta 2-\mathrm{m}$ investigated by Biacore T200. For surface plasmon resonance spectroscopy (SPR)-based affinity measurements, $\beta 2-\mathrm{m}$ was covalently coupled on a CM5-chip. Kinetic measurements were performed by injecting seven concentrations $\left((162.8,81.40,40.70,20.35,10.17,5.087,2.544) \times 10^{-8} \mathrm{M}\right)$ of purified VHHs. The obtained data sets were evaluated using the 1:1 Langmuir binding model.

\section{3. $\beta 2-m$ Adsorption Performance of the VHH Immunoadsorbent}

During the immobilization process, about $54 \%$ of the total VHHs in the cell extract had been coupled onto agarose beads using the amino-activated Sepharose CL-6B, which was previously synthesized at a ligand density of $12 \mu \mathrm{mol} / \mathrm{mL}$. The gel was washed with adequate PBS and $1 \mathrm{M} \mathrm{NaCl}$ solution. The protein bound on the resin was calculated by comparing the VHH concentration before and after immobilization and the VHH density was determined as $1.2 \pm 0.3 \mathrm{mg} / \mathrm{mL}$ gel.

As shown in Figure 5, the adsorption of the sorbent to $\beta 2-\mathrm{m}$ was well-fitted with the Langmuir adsorption isotherm. The correlation coefficient $\left(R^{2}\right)$ of the rearranged Langmuir adsorption isotherm model for $\beta 2-\mathrm{m}$ was 0.986 , indicating that the adsorption of $\beta 2-\mathrm{m}$ on the VHH-based immunoadsorbent was consistent with the Langmuir adsorption isotherm model, and the adsorption process was a monolayer process. Meanwhile, the VHH-based immunoadsorbent exhibited several promising characteristics. The maximal adsorptive capacity of the gel was $0.7466 \mathrm{mg} \beta 2-\mathrm{m} / \mathrm{mL}$ settled gel and the $K_{D}$ value was $6.11 \times 10^{-6} \mathrm{M}$ according to the fitting equation.

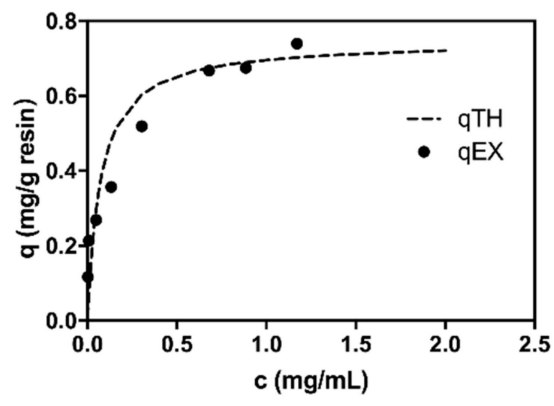

A

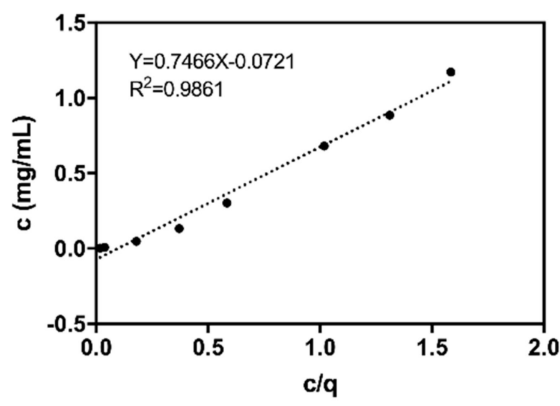

B

Figure 5. The static adsorption performance of the VHH-based adsorbent in plasma. (A) The isothermal adsorption curve of the sorbent at room temperature; qEX represents the test data while qTH represents the theoretical data. (B) The rearranged linearization curve. The slope of the curve was the maximal adsorptive capacity of the gel, and the intercept of curve was the opposite number of $K d$. Y represents the equilibrium concentration of $\beta 2-\mathrm{m} ; \mathrm{X}$ represents $c / q$ (see Equation 2 in Method 3.6).

Reports showed that $1 \mathrm{mg}$ of the conventional IgG antibody could adsorb $0.16 \mathrm{mg}$ of $\beta 2-\mathrm{m}$, while $1 \mathrm{mg}$ of scFv fragment could bind $0.4 \mathrm{mg}$ of $\beta 2-\mathrm{m}$ [17]. When it comes to the VHHs, the theoretical binding capacity of $\beta 2-\mathrm{m}$ for $1 \mathrm{mg}$ of $\mathrm{VHH}(\mathrm{Mr}=1.83 \mathrm{kDa})$ could reach to $0.63 \mathrm{mg}$. The $\beta 2-\mathrm{m}$ binding capacity of the VHH-based adsorbent was better than that of the traditional antibody-based mediums (consisting of traditional whole antibodies or $\mathrm{scFv}$ fragments), as investigated in previous 
studies $[17,27]$. Although the monoclonal antibodies or scFv-based immunoadsorbent could exhibit a high affinity to $\beta 2-\mathrm{m}$, which was superior to the traditional hydrophobic chemical ligands $[14,28]$, they usually present low $\beta 2-\mathrm{m}$ adsorption site density resulting from the inactivation of antibodies by immobilization chemistry (such as cyanogen bromide activation of agarose), leading to limited a portion of immobilized antibodies capable of binding to $\beta 2-\mathrm{m}$. A previous report showed that the immunoadsorbent based on monoclonal antibody $\mathrm{GB}_{5} \mathrm{C}_{7}$ possessed a maximum binding capacity of 100-105 $\mu \mathrm{g} \beta 2-\mathrm{m} / \mathrm{mg}$ of antibody [29]. Another monoclonal antibody-based immunoadsorptive media had a binding site density of only $30 \mu \mathrm{g} \beta 2-\mathrm{m}$ per $\mathrm{mL}$ of settled gel [30]. This VHH-based immunoadsorbent, by contrast, had a significant increase in the $\beta 2-\mathrm{m}$ adsorption capacity.

\subsection{Specific Adsorption Performance of the VHH Immunoadsorbent}

Dynamic binding capacity of $\beta 2-\mathrm{m}$ from plasma was also investigated to evaluate the performance of the VHH-based sorbent. PBS containing $1 \mathrm{M} \mathrm{NaCl}$ was used in washing steps to remove nonspecific adsorption. The final sample eluted by $1 \%$ SDS from the gel was analyzed by SDS-PAGE and showed a good purity (Figure 6B, lane 2). However, a small quantity of FGE also appeared on the gel. FGE was not so stable in alkaline environment that the protein could precipitate on the gel during the coupling process. A purification step would be taken into account after catalysis to remove FGE in future production.

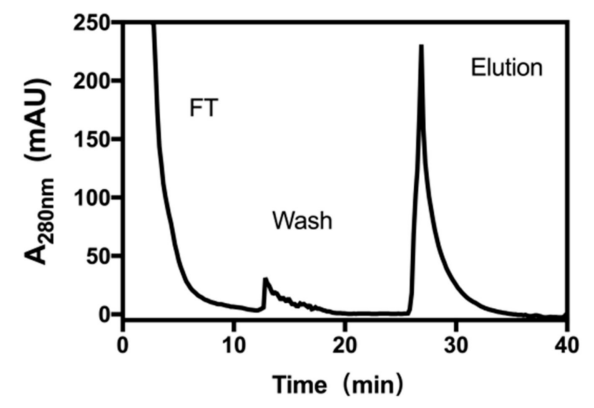

A

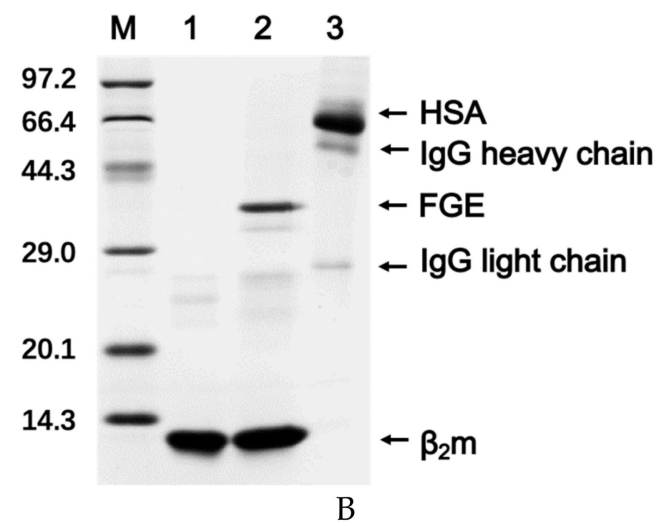

B

Figure 6. Adsorption of $\beta 2-\mathrm{m}$ from $\beta 2$-m enriched human serum using VHH-based immunosorbent fabricated through site-specific reductive amination conjugation. (A) Chromatography profile. (B) SDS-PAGE analysis of the chromatographic fractions. Lane 1, native $\beta 2-\mathrm{m}$; Lane 2, fraction eluted with 1\% SDS; Lane 3, human serum. HSA represents the human serum albumin.

Another in vitro study was performed using the serum to evaluate the non-specific adsorption of the VHH-based immunoadsorbent. It was demonstrated that the matrix exhibited low adsorption to major proteins in blood (shown in Figure 7), which may due to the fact that the binding of $\beta 2-\mathrm{m}$ to $\mathrm{VHH}$ on the beads was based on the specific interaction between antibody and antigen. Although these results proved the specific binding of the adsorbent to $\beta 2-\mathrm{m}$, future studies will focus more on screening VHHs with higher affinity to $\beta 2-\mathrm{m}$ from the phage VHH library for the more efficient removal of $\beta 2-\mathrm{m}$ from blood. 


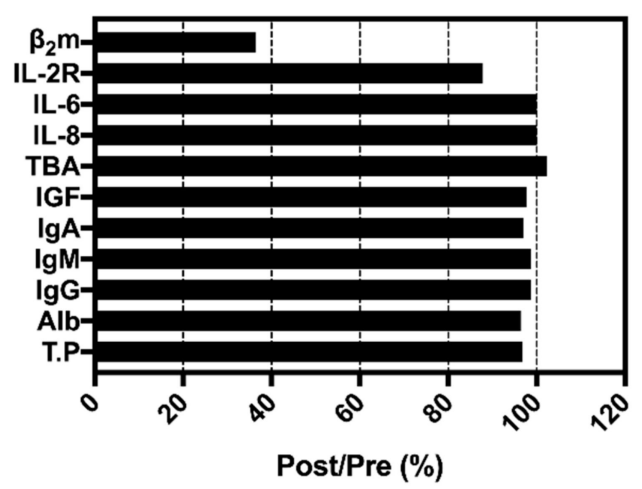

Figure 7. Changes in concentration of serum components before and after the adsorption balance in vitro. T.P, total protein; Alb, albumin; IGF, insulin-like growth factor; TBA, total bile acid; IL-6, interleukin 6; IL-8, interleukin 8; IL-2R, interleukin 2 receptor.

\subsection{Storage Stability of the VHH-based Immunoadsorbent}

The storage stability of the VHH adsorbent was also evaluated. The concentration of VHH that leaked from the gel was almost undetectable, suggesting the reductive amination reaction was a reliable immobilization method to be used on VHHs. Figure 8 shows that the $\beta 2-\mathrm{m}$ binding capacity of the VHH-based immunoadsorbent still remained more than $80 \%$ if that of the freshly prepared sorbent was considered as $100 \%(n=3)$. These results indicated that this one-step prepared VHH-based immunoadsorbent from the crude cell extract via site-specific immobilization was stable.

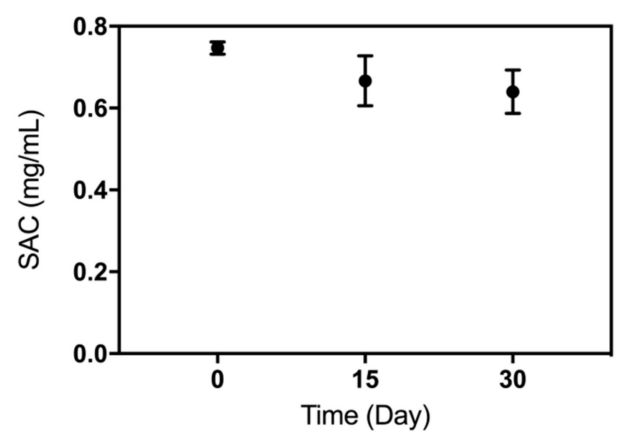

Figure 8. The saturation adsorption capacity (SAC) of the VHH-based immunoadsorbent preserved at $4{ }^{\circ} \mathrm{C}$ for one month (each experiment was performed three times).

In summary, due to the facile production of the aldehyde-tagged proteins and readily accessible bioconjugate strategy, we fused aldehyde tags on the sequence of a VHH antibody, which had a high affinity towards $\beta 2-\mathrm{m}$. Then, the aldehyde loaded protein was introduced onto a DADPA-prepared sephorose to generate novel affinity adsorption resins, possessing a binding capacity of $0.75 \mathrm{mg} \beta 2-\mathrm{m}$ per $\mathrm{mL}$ of settled gel. Furthermore, VHH antibodies can be easily expressed in microbial vectors and site-specifically modified without the loss of activity due to their stability and robustness, potentially reducing the production cost.

\section{Materials and Methods}

\subsection{Reagents and Equipment}

The plasmids pET21a and pET28a were obtained from Novagen (Madison, WI, USA). Strains Escherichia coli Shuffle T7, BL21 (DE3) were purchased from Takara Biotechnology (Dalian, China). Human $\beta 2-m$ was purchased from Crown Medical-Tech (Dalian) Co., Ltd. Sepharose CL-6B was purchased from GE Healthcare (Uppsala, Sweden). Lucifer Yellow $\mathrm{CH}$ probes (LY-CH) was purchased 
from Molecular Probes (Eugene, OR, USA). Human serum was obtained from Blood Bank of Dalian (Dalian, China). The 1,4-Butanediol diglycidyl ether was purchased from J\&K Chemical (Beijing, China). The 2,2' 2-Nitrilotris (ethanol) was purchased from Aladdin Industrial Corporation. The 3,3'-diaminodipropylamine (DADPA) was purchased from Tokyo Chemical Industry (Tokyo, Japan). Double distilled water was obtained from a Milli-Q ultrapure water purification system (Millipore; Billerica, MA, USA).

\subsection{Expression of VHH Antibody and FGE}

The gene of the aldehyde-tagged VHH was cloned into the expression vector pET21a (Novagen) via the restriction sites NdeI and XhoI. The amino acid sequence encoding the $6 \times$ Histag and the aldehyde-tag (LCTPSR) was added to C-terminus of the VHH, registered as the plasmid pET21a-Aldtag-VHH. The plasmid was transferred into E. coli shuffle T7, which was then spread on the lysogeny broth (LB) agar plate $(\mathrm{NaCl} 10 \mathrm{~g} / \mathrm{L}$, tryptone $10 \mathrm{~g} / \mathrm{L}$, yeast extract $5 \mathrm{~g} / \mathrm{L}$, agar powder $1.5 \%$ ) containing $100 \mu \mathrm{g} / \mathrm{mL}$ ampicillin. The plate was incubated at $37^{\circ} \mathrm{C}$ overnight. A single positive clone was selected and cultured in $\mathrm{LB}$ for several hours until the $\mathrm{OD}_{600}$ reached 2.0. After that, terrific broth (TB) containing $100 \mu \mathrm{g} / \mathrm{mL}$ ampicillin was used for further culture in large scale. After a further incubation of cells in TB at $37^{\circ} \mathrm{C}$ for $5 \mathrm{~h}$, the expression of the aldehyde-tagged VHHs was introduced by the addition of $0.5 \mathrm{mM}$ isopropyl $\beta$-D-thiogalactoside (IPTG). After cultivation for an additional $20 \mathrm{~h}$ at $18{ }^{\circ} \mathrm{C}$, the cells were gathered by centrifugation at $8000 \times g$ at room temperature for $20 \mathrm{~min}$ and then resuspended in $20 \mathrm{mM}$ PBS (pH 7.4) containing $150 \mathrm{mM} \mathrm{NaCl}$. The fragmentation of cells by a high-pressure homogenizer was performed for the extraction of Aldtag-VHH and the lysate was centrifuged at 10,000× $g$ for $30 \mathrm{~min}$. The clear supernatant was retained and designated as the crude cell extract.

The amino acid sequence encoding the $6 \times$ Histag was also added to C-terminus of the FGE. The sequence of the recombinant FGE was then constructed into the expression vector pET28a and transferred into an E. coli BL21 (DE3) strain. The expression of FGE depended on the similar culture conditions to VHHs, except for the use of kanamycin to replace ampicillin and the addition of $10 \mu \mathrm{M}$ $\mathrm{CuSO}_{4}$ in terrific broth. Subsequently, FGE was purified by means of metal chelating chromatography.

\subsection{Validation of Aldehyde on $\mathrm{VHH}$}

The cell extract was pretreated with $50 \%$ acetic acid solution to get rid of protein impurities on ice. After centrifugation, the buffer was adjusted to $\mathrm{pH} 9$ with $1 \mathrm{M} \mathrm{NaOH}$ solution. Subsequently, the buffer solution was changed to reaction buffer (containing $50 \mathrm{mM} \mathrm{2,2',2-Nitrilotris,} 50 \mathrm{mM} \mathrm{NaCl}$, and $1 \mathrm{mM}$ DTT, pH 9) by buffer exchange using ultrafiltration devices. The catalysis procedure for FGE to contact the recognition site (LCTPSR) on VHH needed to be accomplished in alkaline condition. FGE was expressed and purified by means of metal chelating chromatography. FGE $(10 \mathrm{mg} / \mathrm{mL})$ and the VHH (about $3 \mathrm{mg} / \mathrm{mL}$ in cell extract, which was analyzed by SDS-PAGE and gray scanning) were mixed at a molar ratio of 1:10, and the mixture was incubated at room temperature for $6 \mathrm{~h}$. Subsequently, a hydrazide-containing dye, LY-CH (10 mM), was applied to verify the successful generation of an aldehyde group on the VHH antibody. The $2 \mu \mathrm{L}$ product after catalysis and $1 \mu \mathrm{L} \mathrm{LY}-\mathrm{CH}$ were added to $18 \mu \mathrm{L} \mathrm{0.1} \mathrm{M}$ acetate buffer ( $\mathrm{pH} 4.0$ ). The labeled mixture was incubated at $37^{\circ} \mathrm{C}$ for $2 \mathrm{~h}$. Then, $20 \mu \mathrm{L}$ of the product was analyzed by SDS-PAGE using a 15\% gel and the fluorescent image was obtained with an image recording system (Syngene, Cambridge, UK).

The affinity measurement of VHHs with or without modification towards $\beta 2-\mathrm{m}$ was performed using surface plasmon resonance spectroscopy with a Biacore T200 instrument (GE Healthcare). Both VHHs were purified by means of metal chelating chromatography and gel filtration chromatography to meet the requirements of the purity of VHHs to be analyzed by SPR. $\beta 2-\mathrm{m}$ was covalently immobilized on a CM5-chip (GE Healthcare) according to the standard protocol. $\beta 2-\mathrm{m}$ was coupled to a response of 500 RU. Flow path 1 was activated and blocked to determine background. For kinetic measurement, seven concentrations $\left((162.8,81.40,40.70,20.35,10.17,5.087,2.544) \times 10^{-8} \mathrm{M}\right)$ of the VHHs were injected. The running buffer containing $10 \mathrm{mM}$ PBS, $150 \mathrm{mM} \mathrm{NaCl}$, and 0.05\% surfactant P20 (pH 7.4) was used. 
For the association of VHHs, a flow rate of $30 \mu \mathrm{L} / \mathrm{min}$ for $300 \mathrm{~s}$ was applied, and for the dissociation a flow rate of $30 \mu \mathrm{L} / \mathrm{min}$ for $600 \mathrm{~s}$ was applied. A regeneration solution containing $100 \mathrm{mM} \mathrm{Glycine- \textrm {HCl }}$ $\left(\mathrm{pH}\right.$ 2.0) was used. Measurements were performed at $25^{\circ} \mathrm{C}$. The data was evaluated using the biacore evaluation software.

\subsection{Optimization of the Catalytic Process of VHH in the Cell Extract}

In this study, four factors that influenced the yield of the aldehyde-modified $\mathrm{VHH}$, including raw ratio, concentration of DTT, temperature, and incubation time, were investigated. $\mathrm{VHH}$ in the reaction buffer (containing $50 \mathrm{mM} \mathrm{2,2',2-Nitrilotris,} 50 \mathrm{mM} \mathrm{NaCl}, \mathrm{pH}$ 9) was incubated with FGE at different molar ratios $(160: 1,80: 1,40: 1,20: 1,10: 1,6: 1,3: 1)$. The mixture was then incubated at $20{ }^{\circ} \mathrm{C}$ for $12 \mathrm{~h}$ after the addition of $2 \mathrm{mM}$ DTT. Different concentrations $(2,1,0.5,0.25,0.125,0 \mathrm{mM})$ of DTT was added in the mixture of $\mathrm{VHH}$ and FGE (molar ratio of 10:1) before incubation at $20^{\circ} \mathrm{C}$ for $12 \mathrm{~h}$ to determine the impact of the reductive reagent on the catalytic efficiency. Incubation time (from $2 \mathrm{~h}$ to $24 \mathrm{~h}$ ) was also investigated in a mixture with a set molar ratio of VHH:FGE (10:1) and $2 \mathrm{mM}$ DTT at $20^{\circ} \mathrm{C}$. In addition, temperatures during the incubation were set at $4{ }^{\circ} \mathrm{C}$ and $20^{\circ} \mathrm{C}$, respectively. All the products were analyzed by SDS-PAGE and the amounts of catalytic products were analyzed quantitatively using the software of ImageJ.

\subsection{Fabrication of VHH-Based Immunoadsorbent}

As shown in Figure 9, sepharose CL-6B (10 mL, purchased from GE Healthcare) was washed with water to remove storage preservatives and activated with $32 \%(v / v)$ 1,4-Butanediol diglycidyl ether in a mixture containing $0.35 \mathrm{M} \mathrm{NaOH}$. The mixture was incubated at $20^{\circ} \mathrm{C}$ for $2 \mathrm{~h}$. The gel was washed with acetone, followed by further washing with plenty of water. The activated gel was then incubated with $10 \% 3,3^{\prime}$-diaminodipropylamine (DADPA) at $50{ }^{\circ} \mathrm{C}$ for $12 \mathrm{~h}$ to generate the amino group. After that, $20 \mathrm{~mL}$ 6\% ethanolamine ( $\mathrm{pH}$ 8.6) was added to the gel to block the remaining epoxy group.

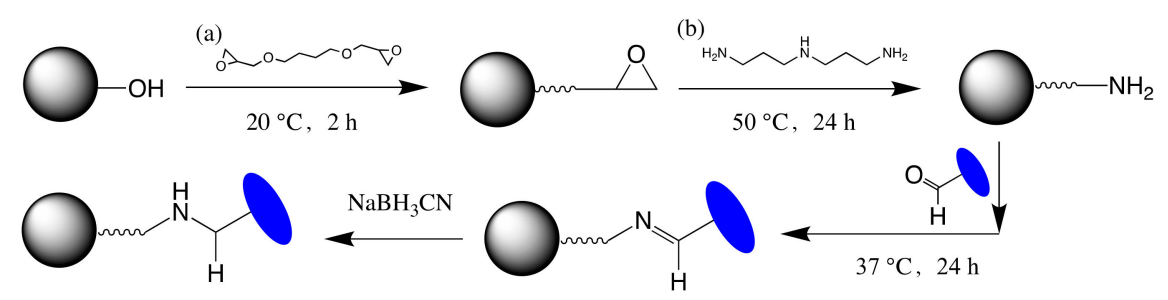

Figure 9. Scheme of the preparation of a VHH based immunoadsorbent: (a) 1,4-butanediol diglycidyl and (b) 3,3'-diaminodipropylamine were used to prepare the amino-activated matrix based on the CL-6B agarose beads. Aldehyde-modified VHHs were then coupled to the matrix via the reductive amination.

Two milligrams of the catalysate were added into one milligram of the DADPA-modified gel, which was washed with the reaction buffer $(\mathrm{pH} 9)$. The coupling process was performed at $37^{\circ} \mathrm{C}$ overnight, followed by washing with several bed volumes of coupling buffer. A further wash step containing $1 \mathrm{M} \mathrm{NaCl}$ was intended to remove nonspecific adsorption to the gel. Collection of all the washes and the amount of protein coupled could be calculated by the difference in the amount of protein present in the reaction medium before and after coupling. The Schiff base bond was reduced with sodium borohydride to prevent a leakage of VHH antibodies from the gel. Finally, the VHH-based immunoadsorbent was stored at $4{ }^{\circ} \mathrm{C}$ in $10 \mathrm{mM}$ PBS containing $0.01 \%$ sodium azide.

\subsection{Adsorption Isotherm in $\beta 2-m$ Enriched Human Serum}

To investigate the adsorption isotherm of $\beta 2-\mathrm{m}$, the human blood serum containing different initial concentrations of $\beta 2-\mathrm{m}(1.3,1.0,0.8,0.4,0.2,0.1,0.05,0.025 \mathrm{mg} / \mathrm{L})$ was used. The gel was washed with PBS and $100 \mu \mathrm{L}$ gel, and was incubated with $500 \mu \mathrm{L}$ of $\beta 2$-m-enriched serum at room temperature under consistent rolling for $2 \mathrm{~h}$. An immunoturbidimetry method was used to determine 
the concentration of $\beta 2-m$ before and after adsorption. The $\beta 2$-m-adsorption capacity and $K_{d}$ of the novel VHH immunoadsorbent were subsequently calculated, using Langmuir adsorption isotherm (Equation 1) and its rearranged equation (Equation (2)).

$$
\begin{gathered}
q=\frac{q_{m} C}{K_{d}+C} \\
C=q_{m} \frac{C}{q}-K_{d}
\end{gathered}
$$

where $C(\mathrm{mg} / \mathrm{mL})$ is the equilibrium concentration of $\beta 2-\mathrm{m} ; q(\mathrm{mg} / \mathrm{mL})$ is the adsorption capacity when the adsorption reaches equilibrium; $q_{m}(\mathrm{mg} / \mathrm{mL})$ represents the maximal adsorption capacity of the gel and $K_{d}$ represents the Langmuir adsorption constant.

\subsection{Specific Adsorption}

The immunoadsorption procedure was performed on the AKTA Purifier 100 (GE Healthcare; Chiltern, Buckinghamshire, UK). Human serum used in this experiment was supplemented with $1 \mathrm{mg} / \mathrm{mL}$ purified $\beta 2-\mathrm{m}$ provided by Crown Medical-Tech (Dalian, China) Co., Ltd. The mixture $(2 \mathrm{~mL})$ was applied to one milligram of the immunoadsorptive gel, which was filled in a cylindrical shell and previously equilibrated with $10 \mathrm{~mL}$ PBS $(10 \mathrm{mM}, \mathrm{pH} 7.4)$ at a linear flow rate of $150 \mathrm{~cm} / \mathrm{h}$. Non-specifically bound components were washed out with PBS (Phosphate buffer) containing $1 \mathrm{M}$ $\mathrm{NaCl}$. Bound $\beta 2-\mathrm{m}$ was then eluted with either $1 \%$ SDS (sodium dodecyl sulfate) or $20 \mathrm{mM}$ glycine- $\mathrm{HCl}$ ( $\mathrm{pH}$ 2.0). The fraction eluted from the gel was then analyzed by SDS-PAGE.

An in vitro study was performed to evaluate the adsorption performance of the VHH-based immunoadsorption to major proteins in blood. Five volumes of the serum were incubated with 1 volume of the adsorbent for $2 \mathrm{~h}$ at room temperature. The native CL-6B matrix without VHH-immobilization served as a blank control group. The concentration of total protein was determined by biuret method. The specific combination of the bromocresol green (BCG) with serum albumin made use of assaying for serum albumin. The concentrations of other components in serum before and after the adsorption equilibrium were determined by immunoturbidimetry or immunohistochemical analysis.

\subsection{Storage Stability of the VHH-Based Immunoadsorbent}

The immunoadsorbent was preserved in $10 \mathrm{mM}$ PBS supplemented with $0.01 \%$ sodium azide at $4^{\circ} \mathrm{C}$ for different periods of time $(0,15,30$ day). The concentration of VHH released from the gel was measured by a BCA method. The $\beta 2$-m adsorption capacity was determined by adsorption isotherm.

\section{Conclusions}

To our knowledge, this was the first time that a VHH-based adsorbent was fabricated by one-step method for the extracorporeal removal of $\beta 2-\mathrm{m}$ from serum. Under the optimized conditions, we confirmed that the $\mathrm{VHH}$ antibody prepared immunoadsorbent was a promising candidate to overcome the problems concerning the specificity and affinity of $\beta 2-\mathrm{m}$. Meanwhile, the bacterial fermentation versus mammalian cell culture (monoclonal antibody-based immunoadsorbents) made the fabrication of the VHH-based immunoadsorbent more cost-effective. Anti- $\beta 2-\mathrm{m}$ VHHs expressed in Escherichia coli had the required affinity to lower $\beta 2$-m concentrations to normal levels. All these results showed the feasibility of the VHH-based immunoadsorbent to get rid of $\beta 2-\mathrm{m}$ from plasma. Future studies will focus on the search for versatile immobilization chemistries to achieve a higher VHH-coupling and $\beta 2-\mathrm{m}$ binding site density.

Author Contributions: Conceptualization, B.Z and L.J.; formal analysis, L.Z.; funding acquisition, J.R. and L.J.; investigation, L.Z.; methodology, L.Z., B.Z., and C.H.; supervision, L.J.; writing一original draft L.Z.; writing—review and editing, L.Z., B.Z., C.H., J.R., and L.J. 
Funding: This study was supported by the Fundamental Research Fund for the Central Universities (DUT19LAB31), National Key Technologies R\&D Program (2016YFC1103002), Dalian Key Technology R\&D Program (2018YF22SN062), and the Dalian Innovation Support Plan for High Level Talents (2016RQ023).

Acknowledgments: The authors would like to acknowledge all the financial supports and all the participating experts. The authors also acknowledge the School of Bioengineering, Dalian University of Technology.

Conflicts of Interest: The funders had no role in the design of the study; in the collection, analyses, or interpretation of data; in the writing of the manuscript, or in the decision to publish the results.

\author{
Abbreviations \\ VHH variable region of the heavy chain antibody \\ FGE formylglycine-generating enzyme \\ ß2-m $\quad \beta 2$-microglobulin \\ scFv single-chain variable fragment \\ HSA human serum albumin
}

\title{
References
}

1. Levey, A.S.; Eckardt, K.U.; Tsukamoto, Y.; Levin, A.; Coresh, J.; Rossert, J.; de Zeeuw, D.; Hostetter, T.H.; Lameire, N.; Eknoyan, G. Definition and classification of chronic kidney disease: A position statement from Kidney Disease: Improving Global Outcomes (KDIGO). Kidney Int. 2005, 67, 2089-2100. [CrossRef] [PubMed]

2. Levey, A.S.; Coresh, J.; Balk, E.; Kausz, A.T.; Levin, A.; Steffes, M.W.; Hogg, R.J.; Perrone, R.D.; Lau, J.; Eknoyan, G. National kidney foundation practice guidelines for chronic kidney disease: Evaluation, classification, and stratification. Ann. Intern. Med. 2003, 139, 137-147. [CrossRef] [PubMed]

3. Eknoyan, G.; Levin, N.W. K/DOQI clinical practice guidelines for chronic kidney disease: Evaluation, classification, and stratification-Foreword. Am. J. Kidney Dis. 2002, 39, S14-S266.

4. Gejyo, F.; Homma, N.; Suzuki, Y.; Arakawa, M. Serum Levels of $\beta$-2-Microglobulin as a New Form of Amyloid Protein in Patients Undergoing Long-Term Hemodialysis. New Engl. J. Med. 1986, 314, 585-586. [PubMed]

5. Ogawa, H.; Saito, A.; Hirabayashi, N.; Hara, K. Amyloid Deposition in Systemic Organs in Long-Term Hemodialysis-Patients. Clin. Nephrol. 1987, 28, 199-204. [PubMed]

6. Gejyo, F.; Yamada, T.; Odani, S.; Nakagawa, Y.; Arakawa, M.; Kunitomo, T.; Kataoka, H.; Suzuki, M.; Hirasawa, Y.; Shirahama, T.; et al. A New Form of Amyloid Protein Associated with Chronic-Hemodialysis Was Identified as $\beta$-2-Microglobulin. Biochem. Bioph. Res. Co 1985, 129, 701-706. [CrossRef]

7. Warren, D.J.; Otieno, L.S. Carpal-Tunnel Syndrome in Patients on Intermittent Hemodialysis. Postgrad. Med. J. 1975, 51, 450-452. [CrossRef]

8. Vanholder, R.; Massy, Z.A. Progress in Uremic Toxin Research: An Introduction. Semin. Dial. 2009, 22, 321-322. [CrossRef]

9. Kleinman, K.S.; Coburn, J.W. Amyloid Syndromes Associated with Hemodialysis. Kidney Int. 1989, 35, 567-575. [CrossRef]

10. Kazama, J.J.; Maruyama, H.; Gejyo, F. Reduction of circulating $\beta 2$-microglobulin level for the treatment of dialysis-related amyloidosis. Nephrol. Dial. Transpl. 2001, 16, 31-35. [CrossRef]

11. Ameer, G.A. Modalities for the removal of $\beta$ (2)-microglobulin from blood. Semin. Dial. 2001, 14, $103-106$. [CrossRef]

12. Tsuchida, L.; Takemoto, Y.; Sugimura, K.; Yoshimura, R.; Yamamoto, K.; Nakatani, T. Adsorption of endotoxin by $\beta(2)$-microglobulin adsorbent column (Lixelle): The new approach for endotoxinemia. Ther. Apher. 2002, 6, 116-118. [CrossRef] [PubMed]

13. Reiter, K.; Bordoni, V.; Dall'Olio, G.; Ricatti, M.G.; Soli, M.; Ruperti, S.; Soffiati, G.; Galloni, E.; D'Intini, V.; Bellomo, R.; et al. In vitro removal of therapeutic drugs with a novel adsorbent system. Blood Purif. 2002, 20, 380-388. [CrossRef] [PubMed]

14. Furuyoshi, S.; Nakatani, M.; Taman, J.; Kutsuki, H.; Takata, S.; Tani, N. New adsorption column (Lixelle) to eliminate $\beta$ 2-microglobulin for direct hemoperfusion. Ther. Apher. 1998, 2, 13-17. [CrossRef] [PubMed] 
15. Kutsuki, H. $\beta(2)$-microglobulin-selective direct hemoperfusion column for the treatment of dialysis-related amyloidosis. Bba-Proteins Proteom. 2005, 1753, 141-145. [CrossRef] [PubMed]

16. Tsuchida, K.; Takemoto, Y.; Nakamura, T.; Fu, O.; Okada, C.; Yamagami, S.; Kishimoto, T. Lixelle adsorbent to remove inflammatory cytokines. Artif. Organs 1998, 22, 1064-1067. [CrossRef] [PubMed]

17. Grovender, E.A.; Kellogg, B.; Singh, J.; Blom, D.; Ploegh, H.; Wittrup, K.D.; Langer, R.S.; Ameer, G.A. Single-chain antibody fragment-based adsorbent for the extracorporeal removal of $\beta(2)$-microglobulin. Kidney Int. 2004, 65, 310-322. [CrossRef] [PubMed]

18. Floege, J.; Ketteler, M. $\beta(2)$-microglobulin-derived amyloidosis: An update. Kidney Int. 2001, 59, S164-S171. [CrossRef]

19. Wesolowski, J.; Alzogaray, V.; Reyelt, J.; Unger, M.; Juarez, K.; Urrutia, M.; Cauerhff, A.; Danquah, W.; Rissiek, B.; Scheuplein, F.; et al. Single domain antibodies: Promising experimental and therapeutic tools in infection and immunity. Med. Microbiol. Immun. 2009, 198, 157-174. [CrossRef]

20. De Meyer, T.; Muyldermans, S.; Depicker, A. Nanobody-based products as research and diagnostic tools. Trends Biotechnol. 2014, 32, 263-270. [CrossRef]

21. Dumoulin, M.; Conrath, K.; van Meirhaeghe, A.; Meersman, F.; Heremans, K.; Frenken, L.G.J.; Muyldermans, S.; Wyns, L.; Matagne, A. Single-domain antibody fragments with high conformational stability. Protein. Sci. 2002, 11, 500-515. [CrossRef] [PubMed]

22. Zang, B.; Ren, J.; Li, D.; Huang, C.; Ma, H.; Peng, Q.; Ji, F.; Han, L.; Jia, L. Freezing-assisted synthesis of covalent C-C linked bivalent and bispecific nanobodies. Org. Biomol. Chem. 2019, 17, 257-263. [CrossRef] [PubMed]

23. Meury, M.; Knop, M.; Seebeck, F.P. Structural Basis for Copper-Oxygen Mediated C-H Bond Activation by the Formylglycine-Generating Enzyme. Angew. Chem. Int. Edit 2017, 56, 8115-8119. [CrossRef] [PubMed]

24. Knop, M.; Engi, P.; Lemnaru, R.; Seebeck, F.P. In Vitro Reconstitution of Formylglycine-Generating Enzymes Requires Copper(I). Chembiochem 2015, 16, 2147-2150. [CrossRef] [PubMed]

25. Knop, M.; Dang, T.Q.; Jeschke, G.; Seebeck, F.P. Copper is a Cofactor of the Formylglycine-Generating Enzyme. Chembiochem 2017, 18, 161-165. [CrossRef] [PubMed]

26. Alvarez-Barcia, S.; Kastner, J. Copper coordination in formylglycine generating enzymes. Eur. Phys. J. Spec. Top. 2019, 227, 1657-1664. [CrossRef]

27. Nakano, H.; Gomi, H.; Shibasaki, T.; Ishimoto, F.; Sakai, O. An Experimental-Study on Selective Elimination of $\beta$-2-Microglobulin Using Immunoadsorption Method in Patients with Chronic-Renal-Failure. Biomat. Artif. Cell Im. 1991, 19, 61-69. [CrossRef]

28. Davankov, V.; Pavlova, L.; Tsyurupa, M.; Brady, J.; Balsamo, M.; Yousha, E. Polymeric adsorbent for removing toxic proteins from blood of patients with kidney failure. J. Chromatogr. B 2000, 739, 73-80. [CrossRef]

29. Vallar, L.; Costa, P.M.P.; Teixeira, A.; Pfister, M.; Barrois, R.; Costa, P.P.; Rivat, C. Immunoadsorption Procedure as a Potential Method for the Specific $\beta$-2-Microglobulin Removal from Plasma of Patients with Chronic-Renal-Failure. J. Chromatogr. B Biomed. App. 1995, 664, 97-106. [CrossRef]

30. Ameer, G.A.; Grovender, E.A.; Ploegh,H.; Ting, D.; Owen, W.F.; Rupnick, M.; Langer, R. A novel immunoadsorption device for removing beta(2)-microglobulin from whole blood. Kidney Int. 2001, 59, 1544-1550. [CrossRef]

Sample Availability: Samples of the compounds are available from the authors, except the anti- $\beta 2-\mathrm{m}$ VHH antibody.

(C) 2019 by the authors. Licensee MDPI, Basel, Switzerland. This article is an open access article distributed under the terms and conditions of the Creative Commons Attribution (CC BY) license (http://creativecommons.org/licenses/by/4.0/). 